\title{
Fortbildung? Fortbildung!
}

Peter Bachmann

Korrespondenz:

Dr. med. Peter Bachmann Facharzt FMH für Kinderund Jugendpsychiatrie und -psychotherapie

Ahornweg 31

CH-5024 Küttigen

Tel. 0628270606

pbachmann[at]hin.ch
Auch im 42. Jahr meiner ärztlichen Tätigkeit suche ich beträchtlich ehrlich meine Fortbildungspflicht zu erfüllen. Die Vorschriften wurden in meinem Fachgebiet auf Jahresbeginn verschärft. Bisher konnte ich manche Credits mit Intervision erwerben. Da lerne ich viel, von den gleichaltrigen Fachleuten und wohl noch mehr von den viel jüngeren, die weniger Erfahrung, dafür ein Lebensgefühl mitbringen, das dem junger Patientinnen und Patienten ähnlich ist, anders als mein in die Jahre gekommenes. Weitere Credits erwarb ich durch wissenschaftliche Tätigkeit, indem ich junge Fachleute bei kleinen wissenschaftlichen Arbeiten unterstützte. Auch da gibt's zu lernen, ich muss mich in die Themen ernsthaft verbeissen. Nicht wie an Fachtagungen, wo Übersichtsreferate mir suggerieren, ich wisse von

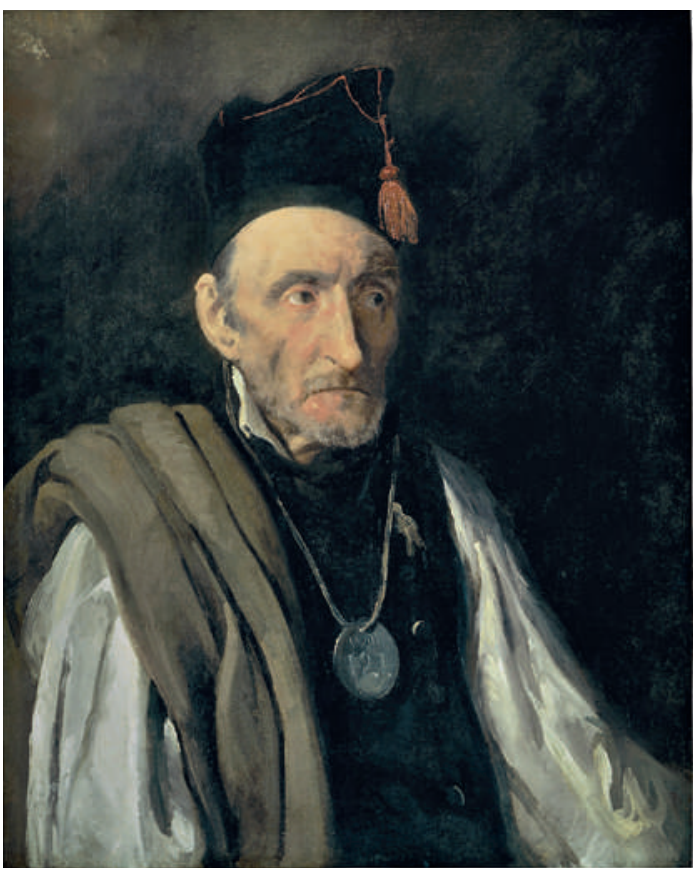

verändert sich signifikant die graue Substanz im linken Gyrus parahippocampalis, linken Gyrus fusiformis ... Die Publikation im Lancet eine medizinische Sensation!

«Am Viertel vor Zähni fahrt de Museumsbus!», höre ich eine leise Stimme. «Am Viertel vor Zähni fahrt de Museumsbus!» Ein Blick in die Runde: überall schweigende, konzentrierte Gesichter. Die Stimme wird lauter und lauter. Da: Kurzschluss vom Hippocampus zum linken Gyrus precentralis. Willenlos steuert mein Organismus aus dem Saal und durch die Strassen. Herr meiner selbst werde ich wieder im Museumsbus, als dessen Tür sich vor der Museumspforte öffnet. Zwischen ästhetischem Genuss und Gewissensbissen hin und hergerissen, bewege ich mich durch die Bildergalerie, bis ich vor Géricaults «Geisteskranker mit miliallem ziemlich genug. Beide Möglichkeiten, Credits $\mathrm{zu}$ sammeln, wurden zahlenmässig stark eingeschränkt, die Bedingungen verschärft. Als CreditLieferanten dominieren anerkannte Fachtagungen.

Sei's denn! Am ersten schönen Vorfrühlingstag fuhr ich zum Kongress nach X. Die Begrüssung war auf 8.30 Uhr, das erste wissenschaftliche Referat auf 9.00 Uhr angesetzt. Ich betrete um 8.50 Uhr den Saal. Stadtpräsident und Spitaldirektor haben bereits gesprochen, jetzt kommt der ärztliche Direktor zum Zug. Die beiden Vorredner hätten schon alles gesagt, äussert er launig, da könne er Zeit einsparen. «Die Botschaft hör ich wohl ...», denke ich. Ja, der Direktor hat dann doch einiges zu sagen, fasst auch kurz die Referenten der ganzen Tagung ins Auge und Wort. Um 9.05 Uhr kommt der Spartenchefarzt, Chairman der Tagung, an die Reihe. Engagiert leitet er ein und würdigt die ersten Referenten. Um 9.15 Uhr ist dann das Wort frei für den Professor aus Birmingham. Meldung aus der Technik: Simultanübersetzungsanlage noch nicht bereit. Flexibel zieht der Chairman sein eigenes Referat vor. Wir erfahren, Frühbehandlung ist sehr wichtig. Auf der Leinwand eine Serie Hirn-MRI-Bilder: Schon in Frühstadien tärischem Grössenwahn» und den zwei Bildern van Goghs aus dem Hospital in Arles stehe. Ja, bin ich denn da nicht mitten im Fortbildungserleben? Etwa mit der Einsicht, dass statt einer Therapeutin ein wärmender Eisenofen dazu dienen kann, Patienten in einer Gruppe zu versammeln.

Gerne würde ich mitteilen, wo diese Bilder zu sehen sind. Aber ich fürchte Repressalien des Klinikfanclubs. Für mich behalte ich auch, wann ich zurück im Tagungszentrum war, wann zur Heimkehr aufbrach.

Im Zug studiere ich die mitgelieferten TagungsAbstracts von Anfang bis Ende, Ehrenwort! Stets futterneidischer Kleinunternehmer, komme ich dann ins ökonomische Sinnieren. 210 Franken bezahlte ich für den einen Tag inkl. Kaffee und niedlichem Stehbuffet zu Mittag. Aussteller-Sponsoren waren auch vor Ort. Teilnehmerzahl über 200. Ergibt überschlagsmässig - nicht schlecht! Doch reisten Referenten aus Melbourne, Birmingham und Dresden an, da ist mit der grossen Kelle anzurichten. Credits können überwiegend nur noch bei anerkannten Tagungen gewonnen werden, die kostenpflichtig sind, 200 Franken da, 300 Franken dort. Die Ta- 
gungssäle werden grösser, organisatorisch werden die Klinikheinzelmännchen (meist -weibchen) durch professionelles Eventmanagement ersetzt. Die Fortbildungsmaschine läuft wie geölt. Gar einiger Glanz scheint auf, wenn zu Tagungsbeginn ein Regierungsrat dem Chairman als «Liebem Jakob» oder «Liebem Philipp» sein Wirken verdankt. Wir applaudieren, bezahlen und dürfen Credits verbuchen.

In der Praxis eingetroffen, räume ich gleich eine Ecke frei für die vielen Fortbildungsprospekte. Nein, den Schweizer Museumsführer stelle ich nicht daneben!
PS: Ist das jetzt nicht doch eine wissenschaftliche Publikation mit mir als Erst- und Letztautor, honorierbar mit 5 Credits? Dann bin ich aber gemäss GCP und aus DUMM verpflichtet, den Standort der Abbildung anzugeben, Klinikfanclub hin oder her. Also: Géricault T. Geisteskranker mit militärischem Grössenwahn. Um 1819-1822. Winterthur: Sammlung Oskar Reinhart «Am Römerholz»; 2012 (www. roemerholz.ch).

(Für Laien: DUMM = Dank für die Unterstützung durch die Museumsmitarbeiterinnen.) 